\title{
Summertime influences of tidal energy advection on the surface energy balance in a mangrove forest
}

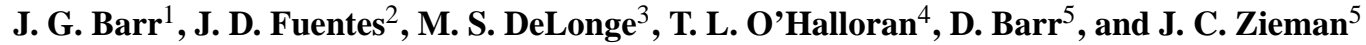 \\ ${ }^{1}$ South Florida Natural Resource Center, Everglades National Park, Homestead, FL, USA \\ ${ }^{2}$ Department of Meteorology, The Pennsylvania State University, University Park, PA, USA \\ ${ }^{3}$ Department of Environmental Science, Policy, and Management, University of California at Berkeley, Berkeley, CA, USA \\ ${ }^{4}$ Department of Environmental Studies, Sweet Briar College, Sweet Briar, VA, USA \\ ${ }^{5}$ Department of Environmental Sciences, University of Virginia, Charlottesville, VA, USA
}

Correspondence to: J. G. Barr (jordan_barr@nps.gov)

Received: 25 July 2012 - Published in Biogeosciences Discuss.: 30 August 2012

Revised: 21 December 2012 - Accepted: 21 December 2012 - Published: 25 January 2013

\begin{abstract}
Mangrove forests are ecosystems susceptible to changing water levels and temperatures due to climate change as well as perturbations resulting from tropical storms. Numerical models can be used to project mangrove forest responses to regional and global environmental changes, and the reliability of these models depends on surface energy balance closure. However, for tidal ecosystems, the surface energy balance is complex because the energy transport associated with tidal activity remains poorly understood. This study aimed to quantify impacts of tidal flows on energy dynamics within a mangrove ecosystem. To address the research objective, an intensive 10-day study was conducted in a mangrove forest located along the Shark River in the Everglades National Park, FL, USA. Forest-atmosphere turbulent exchanges of energy were quantified with an eddy covariance system installed on a 30-m-tall flux tower. Energy transport associated with tidal activity was calculated based on a coupled mass and energy balance approach. The mass balance included tidal flows and accumulation of water on the forest floor. The energy balance included temporal changes in enthalpy, resulting from tidal flows and temperature changes in the water column. By serving as a net sink or a source of available energy, flood waters reduced the impact of high radiational loads on the mangrove forest. Also, the regression slope of available energy versus sink terms increased from 0.730 to 0.754 and from 0.798 to 0.857 , including total enthalpy change in the water column in the surface energy balance for 30-min periods and daily daytime sums, respectively. Results indicated that tidal inunda-
\end{abstract}

tion provides an important mechanism for heat removal and that tidal exchange should be considered in surface energy budgets of coastal ecosystems. Results also demonstrated the importance of including tidal energy advection in mangrove biophysical models that are used for predicting ecosystem response to changing climate and regional freshwater management practices.

\section{Introduction}

Despite their ecological importance, coastal ecosystems remain largely understudied for their capacity to store carbon and cycle energy. For example, the fringe mangrove forests in the Florida Everglades provide a wide range of ecosystem services for local fisheries (Odum and Heald, 1972; Odum et al., 1982) and atmospheric carbon dioxide assimilation (Barr et al., 2010, 2012). Their pan-tropical distribution and continuous growing season permit mangrove forests to exhibit unique carbon and energy cycling patterns (Barr et al., 2010). To fully understand and quantify forest-atmosphere carbon and water vapor exchanges, it is necessary to ascertain the mechanisms and timescales of energy flows through forested systems (Wilson et al., 2002). In mangrove forests, the flow of water during flood and ebb tides may substantially influence the energy transport within the canopy. In terrestrial ecosystems, available energy represents the difference between net radiation $\left(R_{\text {net }}\right)$ and the flux of heat into or out of the soil $(G)$. The available energy $\left(R_{\text {net }}-G\right)$ is then 
partitioned into fluxes of sensible $(H)$ and latent heat (LE) in the vertical direction and heat storage in the biomass and atmosphere below the height where $H$ and LE are determined. Wilson et al. (2002) found that heat storage in the air and in biomass can be significant (7\% of available energy, on average) for tall (>8 m height) vegetated canopies over short (30 min to one hour) time intervals. However, heat stored in biomass was not measured and was therefore neglected in this study. In tidal settings, water inundating the forest floor stores or releases energy as well as carries energy to and from adjacent estuaries. The energy exchange that occurs during flood and ebb tidal cycles must be incorporated into the surface energy budget.

Limited studies have attempted to quantify energy flows in coastal landscapes affected by variable surface water levels. Heilman et al. (1999, 2000) used conditional eddycovariance and Bowen ratio methods to determine the components of the surface energy balance of a coastal marsh near Corpus Christi, TX, USA. Their results showed a poor closure of the surface energy balance that depended on surface water levels and exhibited a strong seasonal signal. Annual energy fluxes revealed that the marsh functioned more like a terrestrial ecosystem, with enhanced latent heat prevailing in the spring during the highest water levels and greatest sensible heat in the summer. In the coastal environment, a clear relationship existed between surface water levels and energy flows. Also, Hoguane et al. (1999) utilized conservation of mass and heat flow equations to estimate temperature and salt dynamics of the Ponta Rasa mangrove swamp in Mozambique. The Ponta Rasa system, which exhibited a twice-daily tide component, was divided into two reservoirs: the Maputo Bay and the mangrove swamp. Results indicated that heat and salt were laterally transported in narrow channels connecting the reservoirs.

In the tidally influenced mangrove forests of the Everglades, FL, USA estuarine waterways flow southwest to the Gulf of Mexico and flood the forest floor up to two times a day (Fig. 1). During low tides in the summer, floodwaters entering from Shark River are generally observed to be cooler than the overlying air in the afternoon, and the receding water transports heat away from the forest floor to the adjacent estuary. The physical process of heat transfer occurs as the cooler water contacts warmer soils below and air above during flood tide periods. During these periods most of the energy exchange occurs across the soil-water and wateratmosphere interfaces at points of water entry into the mangrove forest (the mangrove-estuary interface) and along the soil-water and water-atmosphere interfaces as the tidal waters penetrate into the forest (Barr, 2006). Throughout this manuscript, the terms soils and sediments are used synonymously and interchangeably. These unique energy exchange processes have not been previously explored in coastal systems. It is necessary to understand these energy flows because their temporal variability has implications for fluctuations in soil and air temperature, which influence net ecosys-

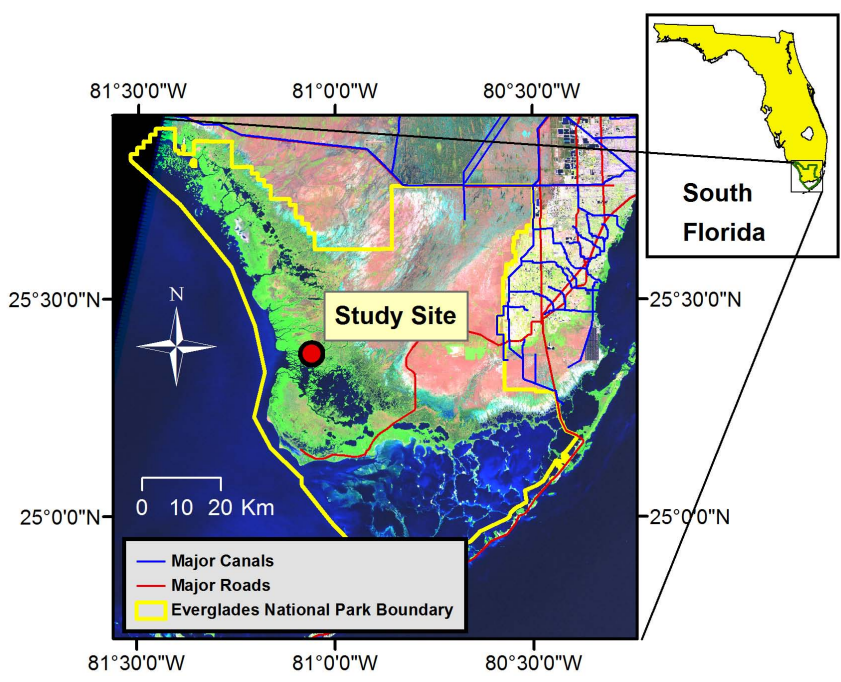

Fig. 1. Landsat 7 thematic map false color composite (RGB bands 5, 4, 3) of southern Florida, USA including the SRS6 study site and flux tower (site SRS6). Mangrove forests appear as bright green along the southwest coast and southern coast adjacent to the Florida Bay.

tem carbon exchange (NEE) over daily and annual timescales (Barr et al., 2012; Ito et al., 2005; van Dijk et al., 2005).

This study aimed to determine the heat flux into the water inundating the soil surface to improve energy budgets for the tidally influenced mangrove forest by accounting for both (i) energy exchange of water recharge (discharge) entering (exiting) the forest from (to) the estuary, and (ii) vertical exchanges of energy at the water-soil and water-atmosphere interfaces. We estimated the vertical transport of energy at the forest-atmosphere interface and the lateral advection of energy by computing the temporal changes in enthalpy of floodwaters during residence within the flux footprint of an eddy covariance (EC) tower. Results were used to understand the mechanics of tidal energy flows and the magnitude of these in relation to vertical exchanges of latent and sensible heat. This work represents a first step toward understanding how tidal energy exchange affects the mangrove microclimate and the consequential influences on physiological processes including photosynthesis and water use efficiency.

\section{Site description}

Located mostly within the boundaries of Everglades National Park (ENP), mangroves represent the dominant primary producers within the coastal Florida Everglades and extend over $1.75 \times 10^{7}$ ha (Lugo et al., 1975). The ENP includes over $4.3 \times 10^{5}$ ha of the Everglades watershed, which is one of the largest freshwater wetland landscapes in North America. The study site was located within a riverine mangrove forest along Shark River (Fig. 1), adjacent to the Florida Coastal Everglades Long-Term Ecological Research (FCE-LTER) 
site 6 in Shark River Slough (SRS6) $\left(25.36462994^{\circ} \mathrm{N}\right.$, $\left.81.07794623^{\circ} \mathrm{W}\right)$. Red (Rhizophora mangle), white (Laguncularia racemosa), and black (Avicennia germinans) mangroves dominate the forest and form a reasonably closed and continuous canopy. The foliage distribution is confined from about $10 \mathrm{~m}$ above the surface to the canopy top $(15 \mathrm{~m}$ on average). The sparse forest understory is comprised primarily of seedlings and juvenile red mangrove trees whose average height is less than $4 \mathrm{~m}$. The wetland peat is up to $6 \mathrm{~m}$ thick and is underlain by limestone bedrock. The top 1-mthick layer of peat consists of compact organic sediments and the mangrove rooting system. The waterways flow southwest to the Gulf of Mexico, and the sediment surface is flooded (Fig. 1) up to two times daily with $0.5 \mathrm{~m}$ of water during high tides. The topography is flat and largely governed by tidal creeks that penetrate the forest. The field study was carried out during 6-16 August 2005 in the middle of the Everglades' wet season. The 10-day study period was representative of summer months characterized by seasonally maximal upstream water levels and daytime air temperatures that exceed water temperatures within the estuary.

\section{Research methodology}

\subsection{Instrumental set-up and data processing}

Energy fluxes and meteorological conditions were quantified based on measurements made from a flux tower, which was located approximately $250 \mathrm{~m}$ inland from the edge of Shark River. An eddy covariance system was used to calculate fluxes of sensible $\left(H_{\mathrm{EC}}\right)$ and latent $\left(\mathrm{LE}_{\mathrm{EC}}\right)$ heat transported across the forest-atmosphere interface (Fig. 2). Vertical wind velocity and temperature were measured at $10 \mathrm{~Hz}$ with a 3-dimensional sonic anemometer (model R3-50, Gill Co., Lymington, England) mounted at $27 \mathrm{~m}$. An adjacent open path infrared gas analyzer (Li-7500, LI-COR Inc., Lincoln, NE, USA) measured water vapor and $\mathrm{CO}_{2}$ concentration at $10 \mathrm{~Hz}$. These measurements were processed with custom-made software to derive half-hourly fluxes of $H$, LE, carbon dioxide $\left(\mathrm{CO}_{2}\right)$, and momentum exchanges between the forest and overlying atmosphere (Barr et al., 2010). Software data processing includes spike removal (Vickers and Mahrt, 1997), a two-dimensional coordinate rotation of the wind field, a time lag correction of $\mathrm{CO}_{2}$ concentration to maximize covariance with vertical wind speed variation (Barr et al., 2010), buoyancy corrections of sonic air temperatures (Schotanus et al., 1983), and calculation of the total constituent flux (Webb et al., 1980) which accounts for positive vertical mass flow resulting from buoyancy of less dense air parcels. Fluxes were determined to be valid if $>50 \%$ of the cumulative flux, using the model of Schuepp et al. (1990), extended within the forest fetch (Fig. 1 in Barr et al., 2010). The flux footprint extended beyond the forest fetch most frequently during the nighttime when winds originated from

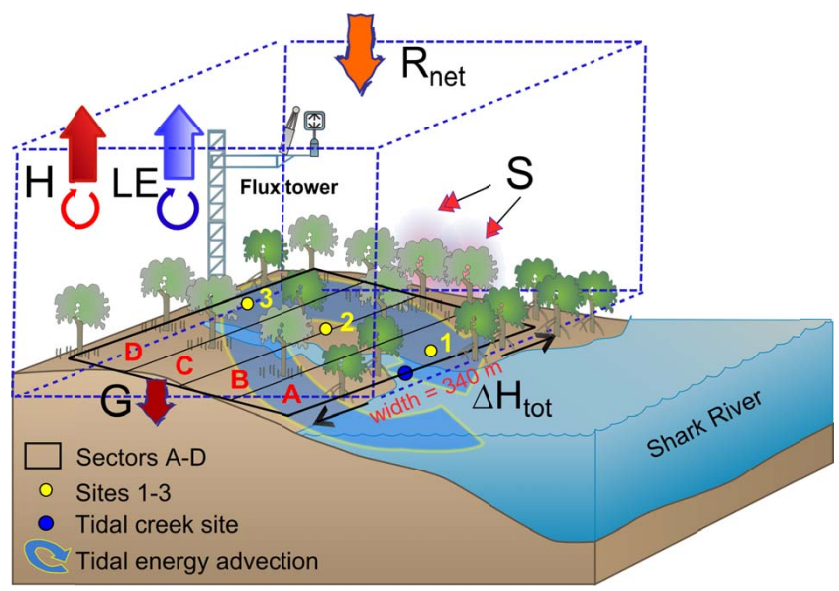

Fig. 2. Conceptual cross section of the study site with key components of the daytime surface energy budget. (When considering the full diel cycles, the fluxes are bidirectional.) Each of sectors A-D has a width $(340 \mathrm{~m})$ perpendicular to the axis of the tidal creek. Inundation level, water temperature, and soil heat flux $(G)$ were measured at sites 1-3. Recharge, water level and temperature were measured within the mouth of the tidal creek site. The $H$ and LE represent the sensible and latent heat exchanges between the mangrove forest and the atmosphere. $\mathrm{S}$ is the sum of heat and biochemical energy storage in biomass. The $\Delta H_{\text {tot }}$ represents the sum of enthalpy change in the water column in the forest $\left(\Delta H_{\text {stor }}\right)$ and heat exchange of water advected $\left(\Delta H_{\mathrm{adv}}\right)$ during recharge (discharge) entering (exiting) the tidal creek.

the NW to NE ( $53 \%$ of the time during the night). Relative humidity at $27 \mathrm{~m}$ was calculated with measurements from a ventilated thermistor-hygristor probe (Model 41382VC, R.M. Young Co., Traverse City, MI, USA). A net radiometer (Model CNR 1, Kipp and Zonen, Delft, Netherlands) recorded net radiation $\left(R_{\text {net }}\right)$. Heat flux plates (model HFT 3-L, Campbell Scientific, Logan, UT, USA) were placed at $0.1 \mathrm{~m}$ below the sediment surface and measured the direction and magnitude of energy flow $(G)$ through the soil. In terrestrial ecosystems, the soil serves as a capacitor for heat, whereby heat is stored during the daytime and released to the atmosphere during the nighttime. However, in mangrove forest ecosystems, the heat is stored (or released) from the overlying water column $\left(\Delta H_{\text {stor }}\right)$ and is transferred $\left(\Delta H_{\text {adv }}\right)$ as a result of water entering (exiting) the forest system during flood (ebb) tides. Barr et al. (2006) defined energy advection as the sum of these terms (i.e., $\Delta H_{\text {stor }}+\Delta H_{\text {adv }}$ ). In this study, the $\Delta H_{\text {stor }}$ and $\Delta H_{\mathrm{adv}}$ are defined separately, and the total contribution of flood waters to the surface energy budget $\left(\Delta H_{\text {tot }}\right)$ is defined as the sum of these terms ( $\Delta H_{\text {stor }}+\Delta H_{\text {adv }}$ ). The magnitude of $\Delta H_{\text {stor }}$ is controlled by (i) heat transfer (conduction) between the sediment and overlying water column, (ii) heat conduction between the water column and the overlying atmosphere, (iii) evaporation at the water-atmosphere interface (removing heat from the water column), (iv) direct absorption of solar irradiance by 
the water column, and (v) mixing of the water column at one temperature with water entering the system at a different temperature. For $\Delta H_{\mathrm{adv}}$, the absolute enthalpy of water entering (exiting) the forest system during flood (ebb) tides is undefined. Therefore, the $\Delta H_{\mathrm{adv}}$ is defined by the amount of heat exchange that occurred in the volume of water that entered (exited) the forest system over a specified time interval.

We quantified energy storage in the water column and lateral energy advection by tides at the study site (Fig. 1) by considering mass and energy budgets for water similar to Hoguane et al. (1999). To obtain spatially accurate temperature and water level gradients, the study site was partitioned into four rectangular sectors, A-D (Fig. 2). Three instrumented locations (Sites 1-3; Fig. 2) were established along a transect extending from the edge of Shark River to the flux tower $(\sim 250 \mathrm{~m})$ and located wholly within the flux footprint of the tower. As in previous studies (Heilman et al., 2000), heat fluxes into or out of the soil were determined at each site using heat flux plates (model HFT 3.1 Heat Flux Plates, Campbell Scientific Inc., Logan, UT, USA) buried $0.1 \mathrm{~m}$ below the sediment surface. Spatially averaged soil heat flux including the 3 sites was used to represent $G$ in Eq. (5) in place of the measurements adjacent to the tower. Measurements included periods when the soil was exposed and inundated during flood tides, but did not include the change in heat storage in the top $10 \mathrm{~cm}$ of sediment since thermistors were not deployed in the peat at the 3 sites. At each site, water temperature was measured with three type E thermocouples (Omega Engineering, Inc., Stamford, CT, USA) deployed at different heights $(0.05,0.13$, and $0.31 \mathrm{~m})$ above the soil surface. A water level sensor (model WL400, Global Water Instrumentation, Inc., Gold River, CA, USA) provided water depth at each site, which was used to identify periods when thermocouples were exposed to the atmosphere. Within the mouth of the tidal creek, E-type thermocouples were also deployed at $0.05,0.13$, and 0.31 , and $0.51 \mathrm{~m}$. Flow velocity in the creek was measured with a flow meter (model Flo-Tote 3, Marsh McBirney, Frederick, MD, USA). Point measurements of velocity at the bottom of the tidal creek were converted to depth- and width-averaged velocity $\left(U\right.$; in $\left.\mathrm{ms}^{-1}\right)$ at $1 \mathrm{~s}$ intervals using results from a vertical flow profile calibration procedure provided in the Flo-Tote 3 User's Manual. Water level, measured by the flow meter's pressure transducer, along with user specified channel widths measured at height increments of 5 to $10 \mathrm{~cm}$, was used to compute instantaneous wetted wall cross-sectional area, $A$ (in $\mathrm{m}^{2}$ ), in $1 \mathrm{~s}$ intervals. Recharge (discharge) quantities $\left(Q ;\right.$ in $\left.\mathrm{m}^{3} \mathrm{~min}^{-1}\right)$ entering (exiting) the tidal creek from Shark River were determined as 10 -min averages as

$$
Q=\left[\int_{t=0}^{600 \mathrm{~s}}(U A) \mathrm{d} t\right] / 10 \mathrm{~min} .
$$

Water temperature $\left(\bar{T}_{i}\right)$ in sectors A-D (Fig. 2) were determined by assuming a linear temperature gradient between each site and solving for the temperature at the midpoint of each sector along a transect connecting the sites. Water temperatures were vertically and temporally averaged at each site and included only those measurements when thermocouples were submerged. The $\Delta H_{\text {stor }}\left(\mathrm{W} \mathrm{m}^{-2}\right)$ is the drainage area normalized change in enthalpy between the current time period $(i)$ and the previous one $(i-1)$ during the time interval, $\Delta t$, and was determined as

$$
\Delta H_{\text {stor }}=\rho C_{\mathrm{w}}\left(\sum_{j=1}^{n} A_{j} h_{j, i-1}\left(T_{j, i}-T_{j, i-1}\right)\right) /\left(\Delta t \sum_{j=1}^{n} A_{j}\right)
$$

where $\rho$ is the density of water $\left(\mathrm{kg} \mathrm{m}^{-3}\right)$ and $C_{\mathrm{w}}$ is the specific heat capacity of water $\left(4186 \mathrm{~J} \mathrm{~kg}^{-1}{ }^{\circ} \mathrm{C}^{-1}\right)$. The $h_{j}, A_{j}$, and $T_{j}$ are water depth $(\mathrm{m})$, area $\left(\mathrm{m}^{2}\right)$, and average water temperature $\left({ }^{\circ} \mathrm{C}\right)$, respectively, within each of $n(n=4)$ sectors, $j$. The total drainage area of the tidal creek $\left(A_{\text {tot }}=\right.$ $\sum_{j=1}^{n} A_{j}$ ) was determined by calculating the average width of all four sectors, $w$, from a mass balance approach. The $w$ was computed as the slope (Eq. 3) of the linear least-squares regression line of the change in volume $\left(\Delta V_{i}\right)$ at time, $i$ resulting from flow $(Q)$ entering (exiting) the tidal creek during each $10 \mathrm{~min}$ time interval $(\Delta t)$ versus the change (from time, $i-1$ to $i$ ) in the sum of cross sectional area of water inundating the surface in all four sectors (Eq. 3), where $l_{j}$ is the length of each sector parallel to the tidal creek.

$\Delta V_{i}=Q_{i} \Delta t=w \sum_{j=1}^{n}\left(\left(h_{j, i}-h_{j, i-1}\right) l_{j}\right)$

This width was then used to estimate the rectangular area of each sector (Fig. 2) and the change in volume resulting from flow through the tidal creek when the sediment surface was inundated during flood and ebb tides. During tidal inflows (outflows), the change in enthalpy attributed to water entering (exiting) the forest through the tidal creek $\left(\Delta H_{\text {adv }}\right)$ was estimated as

$\Delta H_{\mathrm{adv}}=\rho C_{\mathrm{w}} \sum_{j=1}^{n}\left(A_{j}\left(h_{j, i}-h_{j, i-1}\right)\left(T_{j, i}-T_{\mathrm{cr}, i}\right)\right) /\left(\Delta t \sum_{j=1}^{n} A_{j}\right)(4)$

where $T_{\mathrm{cr}, i}$ is the average water temperature entering (exiting) the mouth of the tidal creek. The $\Delta H_{\mathrm{adv}}$ does not represent the advection of energy due to mass flux, but rather represents the heat transfer occurring as water enters (exits) the forest system during flood (ebb) tides. When $T_{\mathrm{cr}}$ could not be measured due to minimal flow and channel depth, it was assumed that water exited the system at the average temperature $\left(\mathrm{T}_{j, i}\right)$ in the water column in each sector. During those periods, the $\Delta H_{\mathrm{adv}}$ is defined as zero in Eq. (4). Besides minimal tidal creek flows, surface water was also likely transported through seepage through the sediment and overbank flow. Any additional heat transfer that may have occurred as the water flowed through the sediment and into the 
tidal creek or river banks was not measured and was therefore not included in this analysis. However, when water levels were high ( $>0.05 \mathrm{~m}$ above the surface) the flow through tidal creeks was the primary mechanism for export of water into the adjacent river. To ensure mass balance closure, the rate of recharge was determined from the volumetric change across the drainage area of the creek, $A_{\text {tot }}$, in place of direct measurements of flow in the tidal creek. Overall uncertainty in $\Delta H_{\text {stor }}$ and $\Delta H_{\text {adv }}$ was determined by summing the square of relative uncertainties of terms in Eqs. (2) and (4) and taking the square root. Uncertainty in measuring water depths $(\sim 5 \%)$, in temporal temperature changes in water in the creek and above the sediment surface $(\sim 15 \%)$, and in estimating the drainage width of the tidal creek $(\sim 10 \%)$ contributed to a combined uncertainty in both $\Delta H_{\text {tot }}$ and $\Delta H_{\text {stor }}$ of $\sim 20 \%$.

\subsection{The surface energy budget in mangrove forests}

The surface energy balance can then be defined as

$R_{\text {net }}-G-\Delta H_{\text {tot }}-S=H+\mathrm{LE}$,

where $\Delta H_{\text {tot }}$ was included with the available energy $\left(R_{\text {net }}-\right.$ $G$ ) since energy stored or transferred into the water column reduced the energy available for partitioning into vertical turbulent exchanges of $H$ and LE. The $S$ includes energy required to heat (or cool) above-ground biomass between the surface and the eddy covariance height and chemical energy stored during photosynthesis (Gu et al., 2007). A positive value of $S$ indicates that energy is stored in the ecosystem. The magnitude of $S$ can be important ( $\sim 5 \%$ of $\left.R_{\text {net }}\right)$ during short (30 min) time intervals, but is generally negligible ( $<5 \%$ of $R_{\text {net }}$ ) when integrated over one to several days. This study did not include the necessary measurements for estimating S, and was therefore not included in the analysis. The $H$ includes both the sensible heat flux $\left(H_{\mathrm{EC}}\right)$ determined from the EC system at a height $\left(h_{\mathrm{EC}}\right)$ of $27 \mathrm{~m}$ and heating of the air mass from the surface to $27 \mathrm{~m}$ (Tsai et al., 2007) and is given by

$H=H_{\mathrm{EC}}+\rho_{\mathrm{a}} C_{\mathrm{p}} \int_{0}^{h_{\mathrm{EC}}} \frac{\partial \theta}{\partial t} \partial z$,

where $\rho_{\mathrm{a}}$ is the density of air $\left(\mathrm{kg} \mathrm{m}^{-3}\right), C_{\mathrm{p}}$ is the heat capacity of air $\left(\mathrm{J} \mathrm{kg}^{-1} \mathrm{~K}^{-1}\right)$, and $\delta \theta$ is the change in potential temperature $(\mathrm{K})$ since the previous $30 \mathrm{~min}$ time step $(\delta t$; in $\mathrm{sec})$. Likewise, $\mathrm{LE}$ includes both the latent heat flux $\left(\mathrm{LE}_{\mathrm{EC}}\right)$ determined from the EC system and the energy content included in the change in storage of water vapor between the surface and $27 \mathrm{~m}$ and is given by

$\mathrm{LE}=\mathrm{LE}_{\mathrm{EC}}+\rho_{\mathrm{a}} L_{\mathrm{v}} \int_{0}^{h_{\mathrm{EC}}} \frac{\partial q}{\partial t} \partial z$, where $L_{\mathrm{V}}$ is the latent heat of vaporization of liquid water $\left(2444 \mathrm{KJ} \mathrm{kg}^{-1}\right)$, and $q$ is specific humidity $\left(\mathrm{g} \mathrm{H}_{2} \mathrm{O}(\mathrm{kg} \text { air })^{-1}\right)$. In Eqs. (6) and (7), changes in temperature and humidity were determined from the humidity probe mounted at $27 \mathrm{~m}$.

Closure of the surface energy budget was determined as the slope of the least-squares regression line forced through the origin (Wohlfahrt et al., 2010) of daytime half-hourly available energy $\left(R_{\text {net }}-G\right)$ versus energy sink terms in Eq. (5) during the 10-day study period. The slope provided an aggregated average estimate of energy balance closure during the 10-day study, which was invariant with amount of available energy. To account for the possibility that the timescales of energy sinks were not exactly synchronized with available energy input, regressions were also performed using daily sums of daytime available energy (i.e., $R_{\text {net }}-$ $G$ and $\left.R_{\text {net }}-G-\Delta H_{\text {tot }}\right)$ versus daily sums of sink terms $(H+\mathrm{LE})$ in $\mathrm{MJ} \mathrm{m}^{-2}$ per day during the 10-day study. Energy balance closure was also analyzed by determining ratios of the running cumulative sums of daytime available energy versus sums of $(H+\mathrm{LE})$ in $\mathrm{MJ} \mathrm{m}^{-2}$. The analysis was performed separately by both including and excluding $\Delta H_{\text {tot }}$ as a storage term included in the available energy.

\section{Results and discussion}

\subsection{Radiation loads and energy partitioning}

Limited information exists on long-term (>months) sensible and latent heat fluxes for tidally influenced mangroves. To determine whether forest-atmosphere energy exchanges exhibit different patterns during high and low tides, mean daily trends of energy fluxes were estimated for seasonal periods similar to the ones included in the 10-day study. Five months of data (July to September 2004 and July to August 2005) analyzed in Fig. 3 provided a sufficiently long period for identifying such changes in energy partitioning and removed any effect of timing of tides in relation to time of day and magnitude of solar irradiance and $R_{\text {net }}$ (Fig. 3a). Average midday (12:00 to 02:00 p.m.) $R_{\text {net }}$ was higher during low tide periods $\left(580 \pm 216 \mathrm{~W} \mathrm{~m}^{-2}\right)$ compared to high $\left(545 \pm 217 \mathrm{~W} \mathrm{~m}^{-2}\right)$ tide periods. These trends contributed to increased midday $H$ (Fig. 3b) during low $\left(H\right.$ of $158 \pm 87 \mathrm{~W} \mathrm{~m}^{-2}$ ) compared to high tide ( $\mathrm{H}$ of $134 \pm 88 \mathrm{~W} \mathrm{~m}^{-2}$ ) periods. Average midday LE (Fig. 4c) was also higher during low (LE of $289 \pm 118 \mathrm{~W} \mathrm{~m}^{-2}$ ) compared to high tide (LE of $251 \pm 108 \mathrm{~W} \mathrm{~m}^{-2}$ ) periods. Soil heat flux adjacent to the tower (Fig. 3d) was the same during low ( $G$ of $\left.8 \pm 7 \mathrm{~W} \mathrm{~m}^{-2}\right)$ versus high $\left(G\right.$ of $\left.9 \pm 6 \mathrm{~W} \mathrm{~m}^{-2}\right)$ tides during 12:00 to 01:00 p.m. During daytime hours, the soil was a weak source of energy $\left(-2 \pm 5 \mathrm{~W} \mathrm{~m}^{-2}\right.$, on average) in the morning (07:00 a.m. to 10:00 a.m.) and a weak sink of energy $\left(1 \pm 6 \mathrm{~W} \mathrm{~m}^{-2}\right.$, on average) during the afternoon (12:00 to 06:00 p.m.), including both low and high tide periods. While 

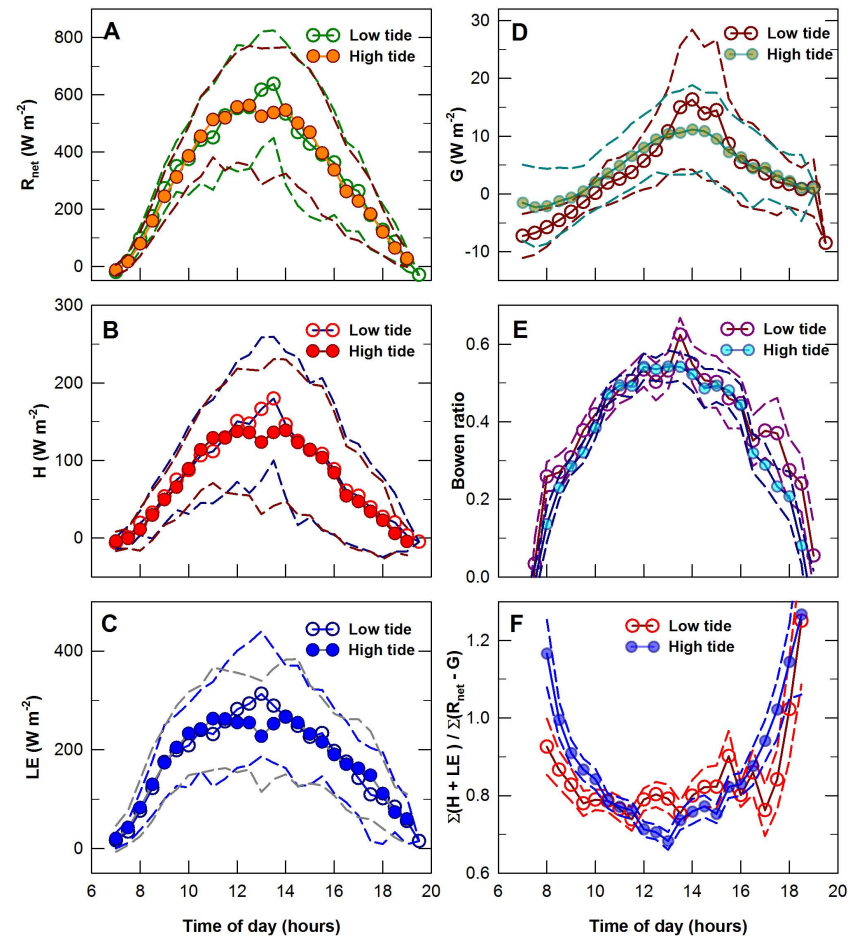

Fig. 3. Mean daily trend (solid lines) \pm 1 s.d. (dashed lines) of net radiation $\left(R_{\text {net }} ; \mathbf{A}\right)$, sensible $(H ; \mathbf{B})$ and latent $(\mathrm{LE} ; \mathbf{C})$ heat fluxes, soil heat flux $(G ; \mathbf{D})$, Bowen ratio $(\mathbf{E})$, and energy balance closure $\left(\Sigma(H+\mathrm{LE}) / \Sigma\left(R_{\text {net }}-G\right) ; \mathbf{F}\right)$ during July to September 2004 and July to August 2005. Flux data were partitioned into periods when the sediment was exposed (low tide) and when the surface was inundated (high tide).

the magnitudes of midday $\mathrm{H}$ and $\mathrm{LE}$ were mostly controlled by $R_{\text {net }}$, the Bowen ratio (H/LE; Fig. 3e) exhibited considerable diurnal variation with minima $(<0.1)$ during the morning (08:00 a.m.) and late afternoon (06:00 p.m.) and maximum values of 0.5 to 0.6 during midday. Inundation status (i.e., high versus low tides) was not observed to control diurnal patterns of the Bowen ratio. This result suggests that the processes controlling surface evaporation changed little comparing the peat surface saturated (or nearly saturated) with water at low tides with a surface covered with water during high tides. The average closure of the surface energy budget $\left(\Sigma(H+\mathrm{LE}) / \Sigma\left(R_{\mathrm{net}}-G\right)\right.$; Fig. 3f $)$ exhibited greater diurnal variation during high tides in comparison with low tide periods. Closure during high tides compared to low tides was greater by 0.05 to 0.24 during the morning (08:00 to 10:00 a.m.) and by 0.02 to 0.18 during late afternoon (05:00 to $06: 00 \mathrm{p} . \mathrm{m}$.) but was lower by 0.02 to 0.10 during the middle of the afternoon (12:00 to 03:30 p.m.). These trends suggest that storage and advection of energy $\left(\Delta H_{\text {tot }}\right)$ in the water column provided, on average, an additional source of energy during the morning and late afternoon (when $R_{\text {net }}$ was lowest) and sink of energy during the middle of the afternoon. Storage of energy by flood waters during mid- afternoon was likely driven by positive air-water temperature gradients when air temperatures were highest and provided a missing sink of energy during high tides. When air temperatures were lower during the morning and late afternoon, mostly negative air-water temperature gradients likely controlled heat release. This process provided a missing source of energy and apparent improved energy budget closure during high tides. These results are consistent with those of Moffett et al. (2010) who found that tidal floodwaters functioned as a heat capacitor in the intertidal salt marshes in San Francisco Bay, USA. During their study in September, floodwaters stored energy during the day and contributed to lower $H$ and LE compared to periods when the marsh was exposed. Their results suggested that tidal flows provided an additional sink of energy during the warm summer months. Sources of water other than tidal flows have been shown to serve as heat capacitors in flooded and coastal ecosystems. Heat stored in the water column during the daytime in a rice paddy in Taiwan (Tsai et al., 2007) represented $7 \%$ of available energy, on average, during a 10-day period in April. Determined from energy budget measurements over a coral reef flat in Australia (McGowan et al., 2010), shallow waters served as a significant sink of energy during the spring as the atmosphere warmed, but waters shifted to a net source of energy to the atmosphere during the winter. In a coastal lagoon in Spain (Rodriguez-Rodriguez and Moreno-Ostos, 2006), groundwater recharge functioned as a heat capacitor by cooling the lagoon during warm summer months and providing a source of energy during the winter.

\subsection{Water flow dynamics and tidal energy advection}

Although topographic changes in the mangrove forest landscape were slight ( $1 \mathrm{~m}$ or less), the differences strongly affected the flow dynamics at the study site. Flow dynamics are illustrated by the time series of water level on the forest floor at three measurement locations within the control volume (Fig. 4a) and within the tidal creek (Fig. 4b). Tidal fluctuations were highly asymmetrical during incoming and outgoing tide. During flood tide, water levels increased rapidly as water was forced through the tidal creek. However, during ebb tide, the flow of water was resisted by soil roughness, the presence of pneumatophores, and obstacles such as coarse woody debris and leaf litter. Except for the presence of large ( $>0.1 \mathrm{~m}$ diameter) logs, many of these resistance elements have a height less than $0.1 \mathrm{~m}$. As a result, flow and therefore change in water level, change noticeably when water levels reach $\sim 0.1 \mathrm{~m}$ at sites 2 and 3 during ebb tides. During these ebb tide periods, a fraction of water percolated through the soil and returned to the river through lateral subsurface flow rather than exiting directly through the tidal creek. Subsurface flow was also evidenced by asymmetric recharge through the tidal creek (Fig. 4c). Flow entering through the creek (i.e., recharge) was visible during each flood tide, but discharge of water exiting the creek during ebb 

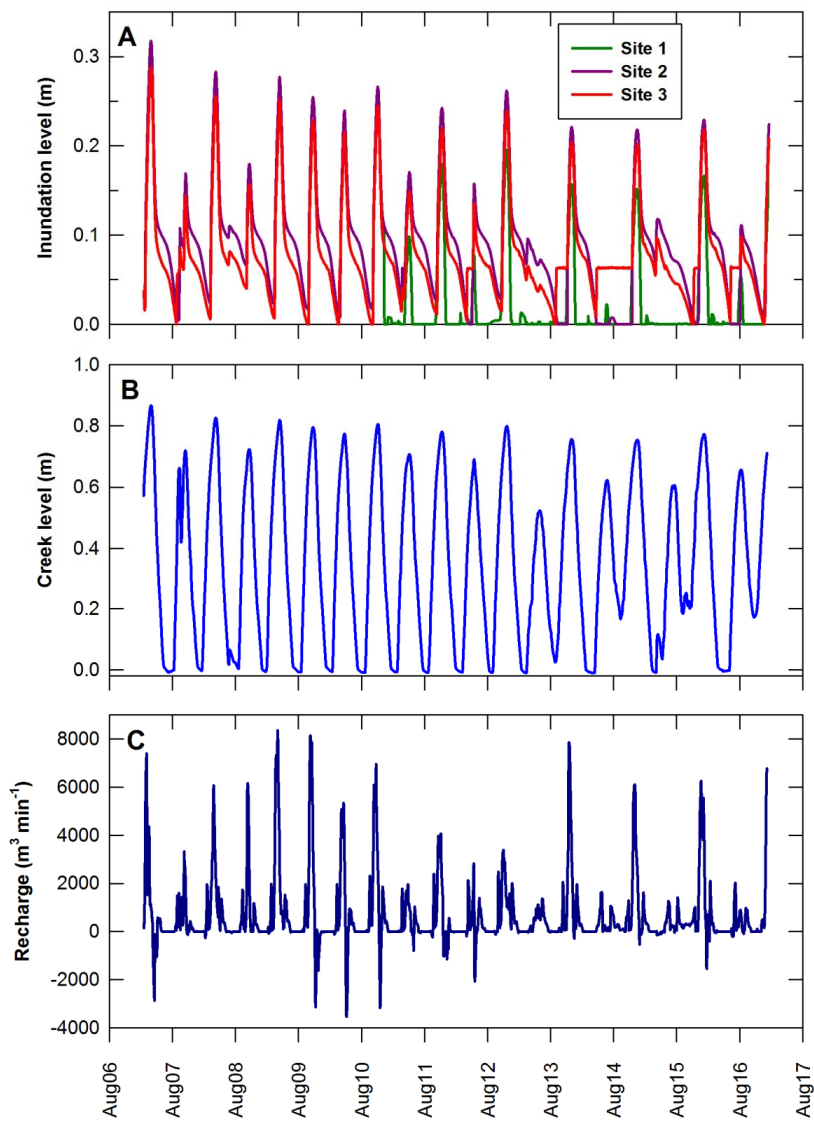

Fig. 4. Water levels inundating the mangrove forest at three measurement locations (Fig. 2) along a transect (A) and within the mouth of the tidal creek (B). Recharge at the mouth of the tidal creek $(\mathbf{C})$ showing flow into the forest (recharge $>0$ ) during flood tide and drainage (recharge $<0$ ) into Shark River during ebb tides.

tides was substantially dampened and in some cases not observed. Much of the remaining water flows overbank or seeps into the sediment and into the creek forced mass balance closure in computing $\Delta H_{\mathrm{adv}}$. The width of the creek drainage was estimated as $340 \pm 34 \mathrm{~m}\left(p<0.05, R^{2}=0.52\right)$ as determined from the slope of the regression line of flow through the creek versus change in cross sectional area in the four sectors (Eq. 3). This large ( $340 \pm 34 \mathrm{~m})$ drainage width provided some context for the asymmetry in creek discharge observed during ebb tide periods.

The timing of tidal flows and inundation (Fig. 4) in relation to available energy represented a key control on the direction and magnitude of $\Delta H_{\text {stor }}$ and $\Delta H_{\text {adv }}$ and therefore on the total change in enthalpy in the water column, $\Delta H_{\text {tot }}$. On 13 August 2005, floodwaters inundated the sediment surface at 06:00 a.m. (Fig. 5a) and preceded the onset of turbulent mixing and increases in $H$ and LE (Fig. 5b). During the flood tide (06:00 to 08:00 a.m.), recharge water provided an initial source of energy $\left(\Delta H_{\mathrm{adv}}<0 \mathrm{~W} \mathrm{~m}^{-2}\right.$; Fig. $\left.5 \mathrm{c}\right)$ to the surface energy budget. Water resting on the sediment surface acted as
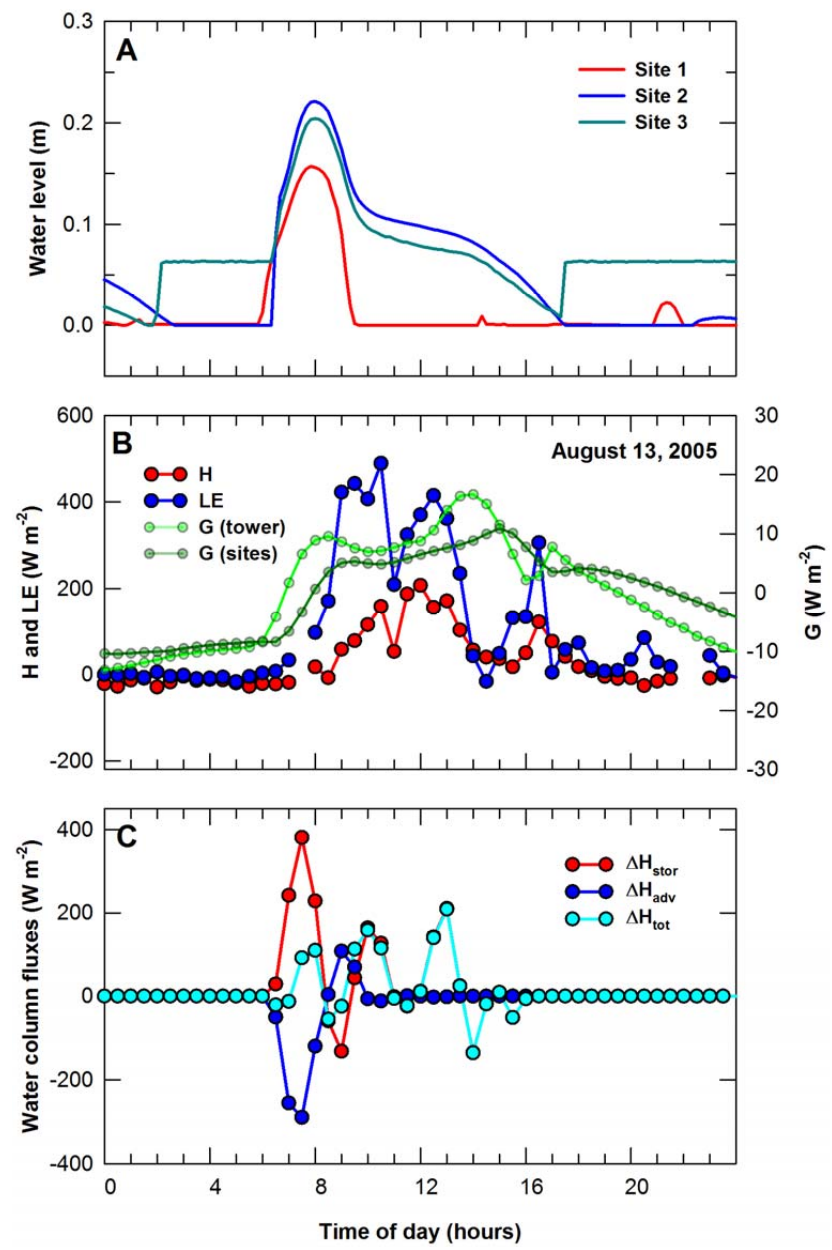

Fig. 5. Diurnal patterns in water level trends at 3 measurement locations (A), sensible $(H)$ and latent (LE) heat fluxes and soil heat fluxes $(G)$ adjacent to the tower and averaged across the 3 sites $(\mathbf{B})$, and enthalpy change in the water column $\left(\Delta H_{\text {stor }}\right)$, resulting from tidal flows $\left(\Delta H_{\mathrm{adv}}\right)$, and total $\left(\Delta H_{\text {tot }}\right)(\mathbf{C})$ on 13 August 2005.

a heat $\operatorname{sink}\left(\Delta H_{\text {stor }}>0 \mathrm{~W} \mathrm{~m}^{-2}\right)$ as warmer recharge waters mixed with cooler flood waters already present on site. The positive $\Delta H_{\text {tot }}$ during 07:00 to 08:00 a.m. was the result of heat conduction across the air-water interface as turbulence increased and solar irradiance was absorbed by the water column. During ebb tide (08:30 to 09:30 a.m.), discharge waters served as a sink of energy $\left(\Delta H_{\mathrm{adv}}>0 \mathrm{~W} \mathrm{~m}^{-2}\right)$, but surface waters transitioned from a source $\left(\Delta H_{\text {stor }}<0 \mathrm{~W} \mathrm{~m}^{-2}\right.$ at 09:00 a.m.) to a sink ( $\left.\Delta H_{\text {stor }}>0 \mathrm{~W} \mathrm{~m}^{-2}\right)$ as discharge proceeded at sites 2 and 3. Overall, the processes of heating of the water column and enthalpy exchange during flood and ebb tides provided a net sink ( $\left.\Delta H_{\mathrm{tot}}\right)$ of $1.12 \mathrm{MJ} \mathrm{m}^{-2}$ of energy on 13 August 2005.

Mean diurnal averages of energy source and sink terms (Fig. 6) were used to understand the role of changes in enthalpy in the water column in the surface energy budget during the 10-day study period when the forest was flooded. The 

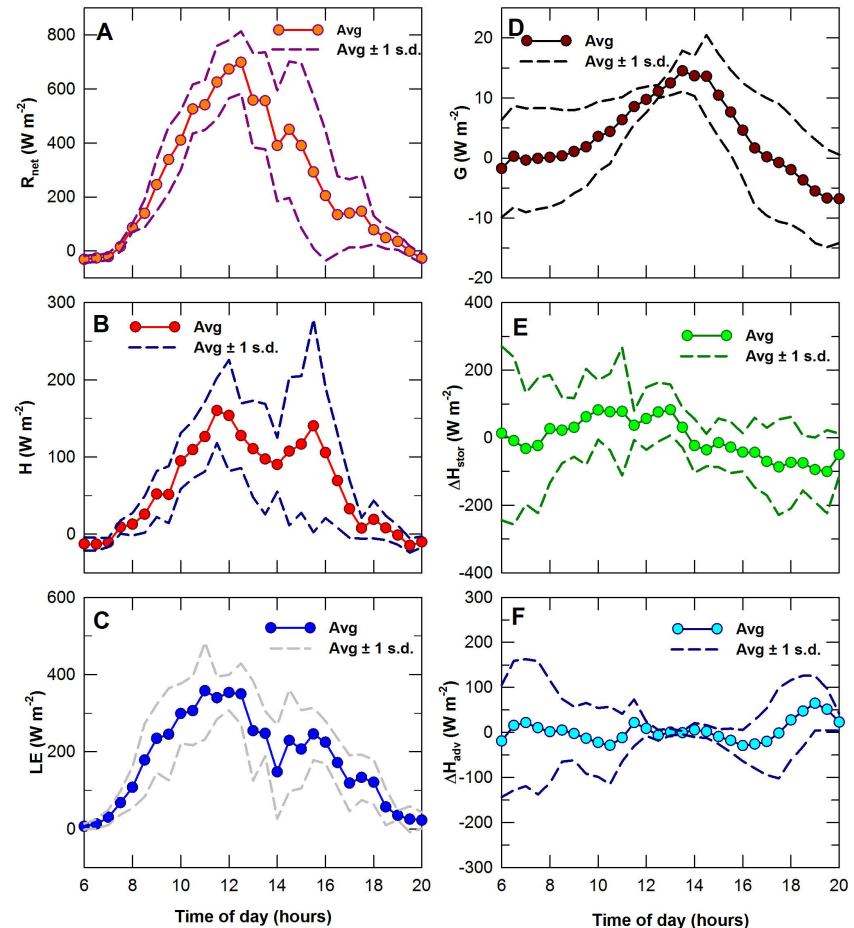

Fig. 6. Diurnal average \pm 1 standard deviation (s.d.) of net radiation $\left(R_{\text {net }} ; \mathbf{A}\right)$, sensible $(H ; \mathbf{B})$ and latent $(\mathrm{LE} ; \mathbf{C})$ heat fluxes, soil heat flux adjacent to the tower $(G ; \mathbf{D})$, change in enthalpy in the water column $\left(\Delta H_{\text {stor }} ; \mathbf{E}\right)$, and that attributed to tidal inflows and outflows $\left(\Delta H_{\mathrm{adv}} ; \mathbf{F}\right)$ during 6-16 August 2005.

$R_{\text {net }}$ (Fig. 6a) was highest $\left(698 \pm 116 \mathrm{~W} \mathrm{~m}^{-2}\right)$ at $12: 30$ p.m. coincident with peak solar irradiance levels (not shown). Both $H$ and LE (Fig. $6 \mathrm{~b}$ and c) peaked prior to the maximum $R_{\text {net }}$ at 11:30 a.m. ( $H$ of $160 \pm 42 \mathrm{~W} \mathrm{~m}^{-2}$ ) and 11:00 a.m. (LE of $358 \pm 126 \mathrm{~W} \mathrm{~m}^{-2}$ ), respectively. Both $\mathrm{H}$ and LE diurnal averages exhibited secondary peaks of $140 \pm 138 \mathrm{~W} \mathrm{~m}^{-2}$ and $246 \pm 68 \mathrm{~W} \mathrm{~m}^{-2}$, respectively, at 03:30 p.m. These midday troughs in ensemble average $H$ and LE were partially attributed to the change in $\Delta H_{\text {stor }}$ (Fig. 6e) from a sink to a source of energy during the early afternoon (01:00 to 03:00 p.m.), and to a lesser extent, the decline in G (Fig. 6d) as a heat sink after 02:00 p.m. This change in $\Delta H_{\text {stor }}$ from a sink to a source of energy was the result of air temperatures dropping below those of floodwaters, which drove heat transfer from the surface to the atmosphere. These secondary peaks in $H$ and LE may also be partly explained by improved closure of the surface energy budget during the afternoon (03:00 to 06:00 p.m.; Fig. 3f), which was not wholly accounted for in diurnal patterns of $\Delta H_{\text {stor }}$ and $\Delta H_{\text {adv }}$ (Fig. 6f).

Though the mean varies diurnally, enthalpy advection processes, represented by $\Delta H_{\text {tot }}$, provided a net sink for energy during the 10-day study period. However, the sign and the magnitude of $\Delta H_{\text {tot }}$ over the course of seasonal cycles likely varied with changes in the temperature gradients between the atmosphere and the waters inundating the surface. Least

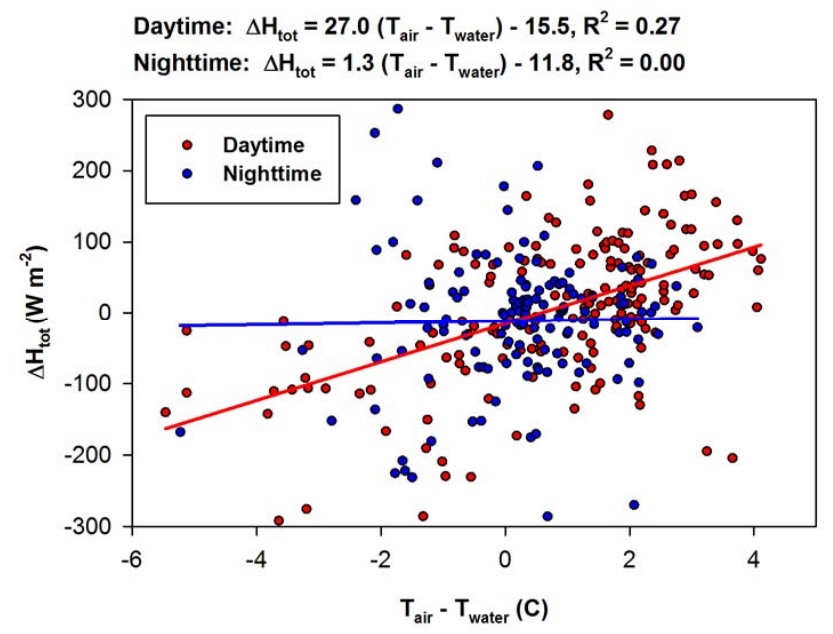

Fig. 7. Daytime and nighttime total enthalpy change in the water column $\left(\Delta H_{\text {tot }}\left(\mathrm{W} \mathrm{m}^{-2}\right)\right)$ as a function of the temperature difference between air temperature $\left(T_{\text {air }}(\mathrm{C})\right)$ at $27 \mathrm{~m}$ and average water temperature $\left(T_{\text {water }}(\mathrm{C})\right)$. The slope of the least squares regression line was significantly different that zero during daytime periods ( $p<0.01, N=181$ ) but not during nighttime periods $(p=0.84$, $N=137)$.

squares regression (Fig. 7) of half-hourly daytime $\Delta H_{\text {tot }}$ versus the difference between air temperature (at $27 \mathrm{~m}$ ) and water temperature (site- and depth-averaged) showed a significant increase $(p<0.01)$ in $\Delta H_{\text {tot }}$ with increasing temperature gradient (slope $=27.0$, intercept $=-15.5, R^{2}=0.27$ ). From this trend line, flood waters are predicted to serve as a source of energy ( $\Delta H_{\text {tot }}<0 \mathrm{~W} \mathrm{~m}^{-2}$ ) when the temperature gradient $\left(T_{\text {air }}-T_{\text {water }}\right)$ is less than $0.6^{\circ} \mathrm{C}$. These results suggests that flood tides should provide the greatest source of energy to the forest surface energy budget during seasonal transitions in October-November, when air masses in south Florida begin to cool but waters in the Gulf of Mexico remain warm. Also, cold fronts lasting for several days frequent the Everglades during December-March. During these periods, floodwaters from Shark River can be warmer than surrounding air at midday and provide a source of heat to the forest. Tidal waters may, therefore, serve to ameliorate extreme microclimatic conditions (associated with extreme heat during the summer or unusual coldness during the winter) within the forest canopy, which detrimentally impact leaf physiology and net ecosystem carbon exchange (Barr et al., 2010).

Including the energy transfer associated with tidal activity improved the closure of the surface energy balance in the mangrove forest during the observation period. When the $\Delta H_{\text {tot }}$ was included in the surface energy budget, its closure improved from 0.730 to 0.754 (Fig. 8a and c, respectively). The regressions between 30-min available energy and energy sinks (Fig. 8a and c) may not fully incorporate diurnal patterns in energy balance closure if time lags exist between $\Delta H_{\text {tot }}$ and turbulent exchange of energy as $H$ and LE. Such 

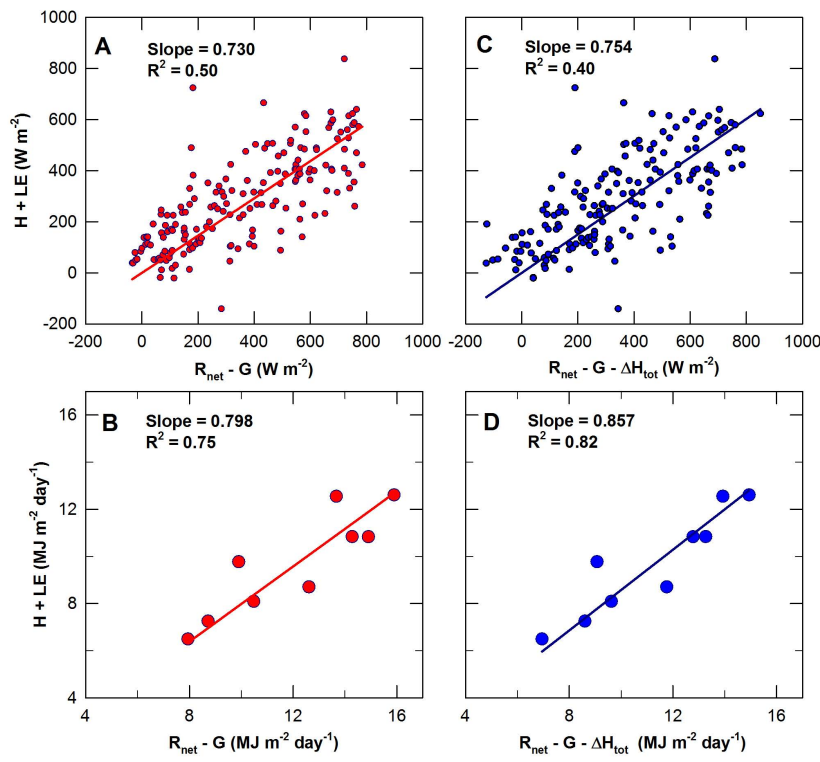

Fig. 8. Half-hourly (A) and daily energy balance closure (B) during 6-16 August 2005 including only daytime periods where available energy is represented as the difference between net radiation $\left(R_{\text {net }}\right)$ and soil heat flux $(G)$. The slope of the regression was $0.730\left(R^{2}=\right.$ $0.50)$ and $0.798\left(R^{2}=0.75\right)$ for half-hourly periods and daily sums, respectively. Half-hourly (C) and daily energy balance closure (D) during 6-16 August 2005 including the total change in enthalpy in the water column in available energy (i.e., $R_{\text {net }}-G-\Delta H_{\text {tot }}$ ). The slope of the regression was $0.754\left(R^{2}=0.40\right)$ and $0.857\left(R^{2}=\right.$ 0.82 ) for half-hourly periods and daily sums, respectively.

temporal lags are suggested by the decline of the coefficient of determination $\left(\mathrm{R}^{2}\right)$ of the regression line from 0.50 to 0.40 by including $\Delta H_{\text {tot }}$ in the surface energy budget. Regressing daily daytime sums of $H$ and LE versus daily available energy appeared to remove temporal lags as evidenced in improved energy balance closure of 0.798 and 0.857 and $R^{2}$ of 0.75 and 0.82 (Fig. 8b and c) in not including and including $\Delta H_{\text {tot }}$, respectively. Regressions using either 30 -min or daily sums of energy fluxes and incorporating $\Delta H_{\text {tot }}$ provided an improvement in closure of the surface energy budget of $2.4 \%$ and $5.9 \%$, respectively. The surface energy budget was also determined from cumulative sums of daytime energy input $\left(R_{\text {net }}-G\right)$ and output (Fig. 9). At the end of the study, cumulative sums of $(H+\mathrm{LE})$ represented $82.2 \%$ and $83.2 \%$ of available energy, respectively (Fig. 9). These estimates of energy balance closure were consistent with those obtained from the slope of the regression (0.798 and 0.857, respectively) of daily sums of energy. Processes that contribute to enthalpy change in the water column (i.e., $\Delta H_{\text {tot }}$ ) should not be ignored for their contribution to the surface energy budget in flooded ecosystems such as rice paddy fields (Gao et al., 2003; Tsai et al., 2007) and ecosystems flooded by high tides such as mangrove forests.

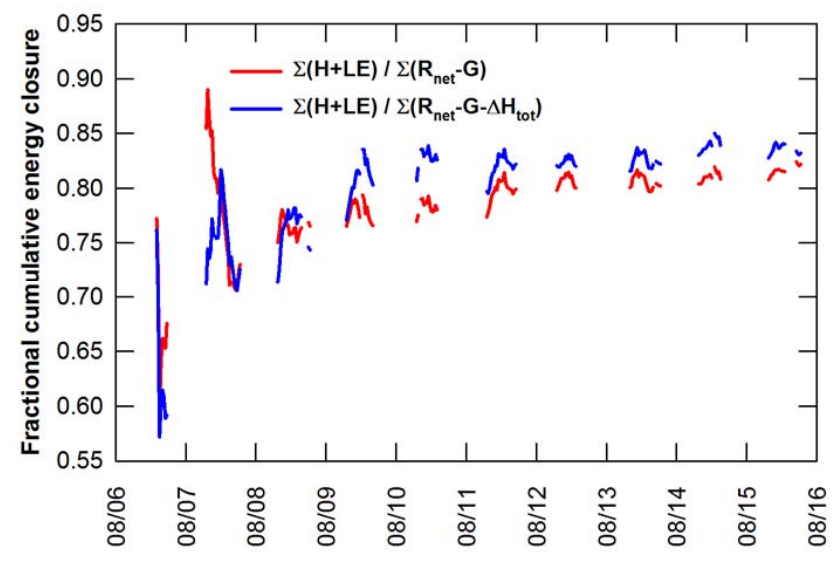

Fig. 9. Fractional cumulative available energy balance closure during the 10-day study period not including $\left(\Sigma(H+\mathrm{LE}) / \Sigma\left(R_{\text {net }}-\right.\right.$ $G))$ and including $\left(\Sigma(H+\mathrm{LE}) / \Sigma\left(R_{\text {net }}-G-\Delta H_{\text {tot }}\right)\right)$ the total change in enthalpy in the water column $\left(\Delta H_{\text {adv }}\right)$ during daytime periods only.

The results for the surface energy balance were within the range of previous findings. The lack of energy budget closure was $20 \%$ for various terrestrial ecosystems (Wilson et al., 2002) but was $\sim 50 \%$ in tidal marsh (Moffett et al., 2010) where advection and sea breezes likely contributed to lack of closure. In other wetlands, such as rice paddy fields, only $5 \%$ to $9 \%$ of the energy budget remained unaccounted (Tsai et al., 2007; Gao et al., 2003). In this study, lack of energy budget closure was $25 \%, 14 \%$, and $17 \%$ based on the 30-min and daily sum regressions and 10-day cumulative sum methods, respectively. In the present study, the "missing" energy likely originated from both underestimating sensible and latent heat fluxes (Sakai et al., 2001) and not accounting for heat storage in biomass and biochemical reactions ( $\mathrm{Gu}$ et al., 2007). The present analysis quantified energy transport occurring in surface waters, which included water inundating the soil surface, mixing of water entering the tidal creek during flood tides, and heat removal prior to discharge during ebb tides. Some net loss of energy likely resulted from subsurface flow and heat exchange with the soil. This subsurface flow did not entirely leave the tidal creeks, but some seeped through interstitial spaces along the steep soil banks lining the adjacent river.

\section{Conclusions}

Results from the present study showed that energy storage and advection associated with tides in a mangrove forest significantly affects the surface energy budget. For the warm periods experiencing high $\left(\sim 800 \mathrm{~W} \mathrm{~m}^{-2}\right)$ net radiation loads, flooding waters provided a net sink for energy mostly through warming of the water column and heat storage $\left(\Delta H_{\text {stor }}\right)$. During ebb tide periods, these warm surface 
waters were discharged into the estuary, thereby preventing release of stored heat during evening hours. The surface energy budget improved by $2.4 \%$ to $5.9 \%$ when the total energy exchange was considered. The positive and significant correlation observed between $\Delta H_{\text {tot }}$ and air-water temperature differences indicated that flood tides provided a microclimate buffer in the mangrove forest ecosystem. Results suggest that during seasonal transitions to cooler air masses, routinely experienced in the Everglades in October and November, warm waters from the Gulf of Mexico would provide an additional source of available energy $\left(\Delta H_{\text {tot }}<0 \mathrm{~W} \mathrm{~m}^{-2}\right)$ when air-water temperature differences drop below $0.6^{\circ} \mathrm{C}$. In this manner, the processes of heat transport during high tides, combined with recharge and discharge through tidal creeks, favor modulation of the surface energy budget in mangrove forests.

Acknowledgements. The Jones Everglades Research Fund provided support to establish the flux tower and to instrument adjacent sites. The National Science Foundation also supported this research through the Florida Coastal Everglades Long-Term Ecological Research (awards DBI-0620409 and DEB-9910514).

Edited by: P. Stoy

\section{References}

Barr, D. A.: Incorporating tidal energy advection into the energy balance for a mangrove forest in the Florida Everglades, M. S. thesis, University of Virginia, Charlottesville, VA, USA, 124 pp., 2006.

Barr, J. G., Engel, V., Fuentes, J. D. Zieman, J. C., O'Halloran, T. L., Smith III, T. J., and Anderson, G. H.: Controls on mangrove forest-atmosphere carbon dioxide exchanges in western Everglades National Park, J. Geophys. Res. Biogeo., 115, G02020, doi:10.1029/2009JG001186, 2010.

Barr, J. G., Engel, V., Smith III, T. J., and Fuentes, J. D.: Hurricane disturbance and recovery of energy balance, $\mathrm{CO}_{2}$ fluxes and canopy structure in a mangrove forest of the Florida Everglades, Agr. Forest Meteorol., 153, 54-66, 2012.

Gao, Z., Bian, L., and Zhou, X.: Measurements of turbulent transfer in the near-surface layer over a rice paddy in China, J. Geophys. Res., 108, 4387, doi:10.1029/2002JD002779, 2003.

Gu, L., Meyers, T., Pallardy, S. G., Hanson, P. J., Yang, B., Heuer, M., Hosman, K. P., Liu, Q., Riggs, J. S., Sluss, D., and Wullschlegger, S. D.: Influences of biomass heat and biochemical energy storages on the land surface fluxes and radiative temperature, J. Geophys. Res., 112, D02107, doi:10.1029/2006JD007425, 2007.

Heilman, J. L., Cobos, D. R., Hensch, F. A., Campbell, C. S., and McInnes, K. J.: Tower-based conditional sampling for measuring ecosystem-scale carbon dioxide exchange in coastal wetlands, Estuaries, 22, 584-591, 1999.

Heilman, J. L., Heinsch, F. A., Cobos, D. R., and McInnes, K. J.: Energy balance of a high marsh on the Texas Gulf Coast: Effect of water availability, J. Geophys. Res., 105, 22371-22377, 2000.

Hoguane, A. M., Hill, A. E., Simpson, J. H., and Bowers, D. G.: Diurnal and tidal variation of temperature and salinity in the Ponta
Rasa mangrove swamp, Mozambique, Estuar. Coast. Shelf S., 49, 251-264, 1999.

Ito, A., Saigusa, N., Murayama, S., and Yamamoto, S.: Modeling of gross and net carbon dioxide exchange over a cool-temperate deciduous broad-leaved forest in Japan: Analysis of seasonal and interannual change, Agr. Forest Meteorol., 134, 122-134, 2005.

Lugo, A. E., Evink, G., Brinson, M. M., Broce, A., and Snedaker, S. C.: Diurnal rates of photosynthesis, respiration, and transpiration in mangrove forests of south Florida, in: Tropical Ecological Systems Trends in Terrestrial and Aquatic Research, edited by: Golley, F. B. and Medina, E., Springer, New York, 335-350, 1975.

McGowan, H. A., Sturman, A. P., MacKellar, M. C., Wiebe, A. H., and Neil, D. T.: Measurements of the local energy balance over a coral reef flat, Heron Island, southern Great Barrier Reef, Australia, J. Geophys. Res., 115, D19124, doi:10.1029/2010JD014218, 2010.

Moffett, K. B., Wolf, A., Berry, J. A., Gorelick, S. M.: Salt marshatmosphere exchange of energy, water vapor, and carbon dioxide: Effects of tidal flooding and biophysical controls, Water Resour. Res., 46, W10525, doi:10.1029/2009WR009041, 2010.

Odum, W. E. and Heald, E. J.: Trophic analysis of an estuarine mangrove community, B. Mar. Sci., 22, 671-738, 1972.

Odum, W. E., McIvor, C. C., and Smith, T. S.: The ecology of mangroves of South Florida: a community profile, US Fish and Wildlife Service, Office of Biological Services, Washington DC, FWS/OBS - 81/24, 1982.

Rodriguez-Rodriguez, M. and Moreno-Ostos, E.: Heat budget, energy storage and hydrological regime in a coastal lagoon, Limnologica, 36, 217-227, 2006.

Sakai, R. K., Fitzjarrald, D. R., and Moore, K. E., Importance of low-frequency contributions to eddy fluxes observed over rough surfaces, J. Appl. Meteorol., 40, 2178-2192, 2001.

Schotanus, P., Nieuwstadt, F. T. M., and De Bruin, H. A. R.: Temperature measurement with a sonic anemometer and its application to heat and moisture fluctuations, Bound-Lay. Meteorol., 26, 81-93, doi:10.1007/BF00164332, 1983.

Schuepp, P. H., LeClerc, M. Y., Macpherson, J. I., and Desjardins, R. L.: Footprint prediction of scalar fluxes from analytical solutions of the diffusion equation, Bound-Lay. Meteorol., 50, 355373, 1990.

Tsai, J.-L., Tsuang, B.-J., Lu, P.-S., Yao, M-H., and Shen, Y.: Surface energy components and land characteristics of a rice paddy, J. Appl. Meteorol. Clim., 46, 1879-1900, doi:10.1175/2007JAMC1568.1, 2007.

van Dijk, A. I. J. M., Dolman, A. J., and Schulze, E. D.: Radiation, temperature, and leaf area explain ecosystem carbon fluxes in boreal and temperate European forests, Global Biogeochem. Cy., 19, GB2029, doi:10.1029/2004GB002417, 2005.

Vickers, D. and Mahrt, L.: Quality control and flux sampling problems for tower and aircraft data, J. Atmos. Ocean. Tech., 14, 512 526, 1997.

Webb, E. K., Pearman, G. I., and Leuning, R.: Correction of the flux measurements for density effects due to heat and water vapor transfer, Q. J. Roy. Meteor. Soc., 106, 85-100, doi:10.1002/qj.49710644707, 1980.

Wilson, K. B., Goldstein, A., Falge, E., Aubinet, M., Baldocchi, D., Berbigier, P., Bernhofer, C., Ceulemans, R., Dolman, H., Field, C., Grelle, A., Ibrom, A., Law, B. E., Kowalski, A., Meyers, T., 
Moncrieff, J., Monson, R., Oechel, W., Tenhunen, J., Valentini, R., and Verma, S.: Energy balance closure at FLUXNET sites, Agr. Forest Meteorol., 113, 223-243, 2002.
Wohlfahrt, G., Irschick, C., Thalinger, B., Hortnagl, L., Obojes, N., and Hammerle, A.: Insights from independent evapotranspiration estimates for closing the energy balance: a grassland case study, Vadose Zone J., 9, 1025-1033, doi:10.2136/vzj2009.0158, 2010. 